\title{
Field Evaluation of the rough mutant Brucella abortus $R B 51$ vaccine in cattle
}

\author{
H. I. Hosein', M. N. El-Sheary' ${ }^{2}$, A. M. El-Sherif', K. M. S. Ibrahim ${ }^{2}$ \\ ${ }^{1}$ Deptartment of Veterinary Medicine, Faculty of Veterinary Medicine, Beni-Suef, Cairo University, Egypt \\ ${ }^{2}$ Deptartment of Veterinary Medicine, Faculty of Veterinary Medicine Suez Canal University, Egypt
}

In this study field application of RB51 vaccine combined with the policy of test and slaughter as well as application of hygienic measures for control of bovine brucellosis were carried out and evaluated in a dairy herd of cattle for two years. Serological examination of 1280 cattle using tube agglutination, buffered acidified plate antigen, Rose Bengal plate antigen and Rivanol tests revealed $240(18.75 \%)$ positive animals with a previous history of abortion of 12 cows.

Brucella melitensis biovar 3 could be isolated from tissue specimens of slaughtered cows. Animals that tested negative in the first examination were vaccinated with RB 51 vaccine with periodical examination every three weeks and slaughtering of positive cases. New positive cows continued to develop up to the $5^{\text {th }}$ examination then three successive sero-negative tests were obtained with release of the farm from quarantine. Examination of animals 6,12,18 and 24 months post release of quarantine revealed 2, 3,0 and one positive cases respectively the matter which clarified that the control of the outbreak using RB51 vaccine associated with policy of test and slaughter and application of hygienic measures showed some limitations.

Brucellosis is caused by facultative intracellular bacteria of the Genus Brucella, which are capable of survival and multiplication within phagocytes, Nicoletti and Tanya (1993). The disease causes severe economic losses due to abortion, decrease of milk yield and infertility. In addition, brucellosis is a zoonotic disease and readily transmissible through direct and aerosol contract Covert et al. (2005).

Control of brucellosis in livestock is still considered a difficult task. In developed countries the policy aimed at avoiding the economic losses and public health threats through eradication of infected animals. On the other hand the policy of test and slaughter has been used extensively in many developing countries including Egypt, limitations of this policy is mainly due to difficulty of accurate diagnosis of individual cases, Salem et al., (1987), therefore immunization to raise the resistance of cattle against Brucella infection is considered an essential step to prevent spread of infection among susceptible cattle, (Alton, 1990).

The mutant rough Brucella abortus RB51 vaccine has been recently introduced to immunize cattle and replace the smooth Brucella abortus S19 in Egypt, as the rough vaccinal strain does not express significant amount of the
O polysaccharide chain (O-chain) of the lipopolysaccharids (LPS) as reported by Schurig et al., (1991).

The present study was carried out to evaluate the use of RB51 vaccine to immunize cattle associated with the policy of test and slaughter which represents the official policy of control of brucellosis in Egypt.

\section{Material and Methods}

A total of 1280 female cattle in a dairy herd infected with Brucella melitensis biovar 3 under quarantine of the Egyptian veterinary authority were employed in this study. These animals were used for evaluation of RB 51 combined with application of the policy of test and slaughter and hygienic measures. Serologic testing was carried out every three weeks and positive cases were removed and slaughtered under the supervision of the veterinary authority. Serologically negative animals were vaccinated with $\mathrm{RB} 51$ vaccine after the first examination. After release of the farm from quarantine (3 successive negative tests), serological examination continued every 6 months up to 2 years.

Antigens. for tube agglutination, Buffered acidified plate; Rose Bengal plate and Rivanol tests as well as Rivanol solution were obtained from Veterinary Serum and Vaccine Research 
Table (1): Results of serological examination of the dairy herd at the beginning of the outbreak.

\begin{tabular}{ccc}
\hline No. of animals & Sero positive animals & Sero negative animals \\
\hline 1280 & $240(18.75 \%)$ & $1040(81.25 \%)$ \\
\hline
\end{tabular}

*Brucella melitensis biovar 3 was isolated from 10 seropositive slaughtered cows.

Table (2): Results of serological testing during quarantine period and vaccination using RB 51 vaccine.

\begin{tabular}{cccc}
\hline \multirow{2}{*}{ Examination } & No. of animals & \multicolumn{2}{c}{ Serotesting } \\
\cline { 3 - 4 } & & + ve & -ve \\
\hline $\mathbf{1}^{\text {st }}$ & 1280 & 240 & 1040 \\
& Vaccination of $\mathbf{1 0 4 0}$ & animals using RB 51 & 1022 \\
$\mathbf{2}^{\text {nd }}$ & 1040 & 18 & 1010 \\
$\mathbf{3}^{\text {rd }}$ & 1022 & 12 & 1002 \\
$\mathbf{4}^{\text {th }}$ & 1010 & 8 & 994 \\
$\mathbf{5}^{\text {th }}$ & 1002 & 8 & 994 \\
$\mathbf{6}^{\text {th }}$ & 994 & 0 & 994 \\
$\mathbf{7}^{\text {th }}$ & 994 & 0 & 994 \\
$\mathbf{7}^{\text {th }}$ & 994 & 0 & 994 \\
$\mathbf{8}^{\text {th }}$ & 994 & 0 & \\
\hline
\end{tabular}

Table (3): Results of serological examination of the cattle after release of quarantine.

\begin{tabular}{cccc}
\hline $\begin{array}{c}\text { Examinations post } \\
\text { release of quarantine }\end{array}$ & No. of cows & \multicolumn{2}{c}{ Results of serotesting } \\
\cline { 3 - 4 } 6 months & 994 & 2 & - ve \\
$\mathbf{1 2}$ months & 992 & 3 & 992 \\
$\mathbf{1 8}$ months & 989 & 0 & 989 \\
$\mathbf{2 4}$ months & 989 & 1 & 989 \\
\hline
\end{tabular}

Institute, Abbasia, Cairo, Egypt. License No 188 was obtained from professional biological company 4950York Street-Denver, Co, USA. Tube agglutination, Buffered acidified plate agglutination and Rivanol tests were carried out according to (Alton et al., 1988). Rose Bengal test was carried out according to Morgan et al., (1978).

Medium. Tryptic soya agar, Difco laboratories, Detroit, MI, USA was used for culturing Brucella organisms. Isolation, Identification and typing of Brucella organisms were carried out according to Alton et al., (1988).

\section{Results and Discussion}

In this study Brucella abortus RB 51 vaccine was used to control an outbreak of brucellosis in cattle combined with application of test and slaughter policy as well as application of sanitary measures. The first examination revealed the presence of $240(18.75 \%)$ positive cows (Table 1), associated with a previous history of abortion of $12 \quad(0.93 \%)$ cows suggesting a recent Brucella infection. All reactors were slaughtered under the supervision of the veterinary authority. Tissue specimens were cultured where Brucella melitensis biovar 3 could be isolated from the supramammary lymph nodes and spleen. This indicates that Brucella melitensis biovar 3 is still the prevalent Brucella biovar in Egypt. Similar findings were reported by (Hosein et al., 2002a and El-Diasty 2004).

All Brucella negative animals were vaccinated after the first examination using RB51 vaccine (Table 2). Then animals were examined every three weeks. Positive cases continued to develop, 18 cases at the $2^{\text {nd }}$ examination, 12 cases at the $3^{\text {rd }}$ examination, 8 
cases at the $4^{\text {th }}$ examination and finally 8 cases at the $5^{\text {th }}$ examination.

Failure of the vaccine to protect animals that developed infection may be attributed to that these animals were vaccinated while incubating the diseases. Another explanation that these animals were exposed to infection before development of protective immunity by the vaccine.

The above mentioned findings indicated that the farm was suffering from a recent Brucella infection with availability of sources of infection which may include positive cases with either abortion or even normal parturition with contamination of the environment with a huge number of Brucella organisms. Presence of carriers such as dogs and rats may contribute in development of positive cases, Hosein et al., (2001). In addition survival of Brucella organisms in pastures can maintain the infection for a considerable period, (Wilson, 1972).

Examination of animals after 6,12,18 and 24 months post release of the farm from quarantine revealed 2, 3, 0 and one Brucella infected cows respectively (Table 3 ). This indicates that release of Brucella-infected farms out of quarantine based on three negative successive serological tests can't be relied upon. Similar observation had been reported by (Hosein et al., 2002a). This indicates the importance of continuous surveillance of infected population. Another important contributing factor in development of new positive cases may be the keeping of brucellainfected animals in the farms before their slaughtering by the veterinary authorities. This is considered a potential source of infection, which facilitates the spread of infection to susceptible animals as explained by El-Gibaly, (1993).

The results obtained in this study indicated that rough mutant Brucella abortus RB 51 vaccine failed to some extent to give the expected promising results. This may be attributed to the early clearance of the RB 51 vaccinal strain from tissues as reported by
Stevens et al., (1995) and Hosein et al., (2002 b) or to the high virulence of the local strain of Brucella melitensis.

\section{References}

Alton, G. G. (1990): Brucella melitensis, 1887 to 1987 cited in Animal Brucellosis by K. Nielsen and J.R. Dun can. CRC Pren. Boston.

Alton, G. G.; Jones, L. M.; Angus, R. D. and Verger, J. M. (1988): Techniques for the Brucellosis laboratory. INRA, Publication, Paris, ISEN, France.

Covert, J.; Eskra, L. and Splitter, G. (2005): Isolation of Brucella abortus RNA from B. abortus infected murine RAW macrophages. J. Microb. Meth., 60:383.

El-Diasty, M. (2004): Epidemiological and Immunological studies on Bovine Brucellosis MVSc. Thesis, Infectious Diseases, Fac. Vet. Med. Suez Canal Univ., Egypt.

El-Gibaly, S. M. (1993): Correlation between serotests and isolation of Brucella melitensis in an infected sheep farm. $2^{\text {nd }}$ Sci. Cong., Egypt. Soc. for Cattle Dis., Assuit, Egypt.

Hosien, H.I.; Dawood, F.Z. and El-Sheery, M.N. (2002a): Evaluation of the policy of test and slaughter for control of brucellosis in Egypt. $10^{\text {th }}$ Sci. Con. 2002, Fact. Vet. Med. Assuit Univ., Egypt.

Hosein, H. I., El-Sheary M. N and Dawood, F. Z. (2002b): A comparative study on the fate and immunogenicity of Brucella melitensis Rev 1, Brucella abortus S19 and RB 51. $10^{\text {th }}$ Sci. Con. 2002, Fac. Vet. Med. Assuit Univ., Egypt.

Hosien, H. I.; Sohair, Y.; Enany, M. and Gabal, M. A. (2001): The role of some Brucella carriers (stray dogs and cats) in maintenance of Brucella infection. Beni-Suef Vet. Med. J., 11 (2): 521-529.

Morgan, W. J. B.; Mackinnon, D. J.; Gill, K. P. W.; Cower S. G. M. and Norris, P. L. W. (1978): Standard laboratory techniques for the diagnosis of brucellosis. Repot Series No., I, Weybridge Cent. Vet. Lab., England.

Nicoletti, P. and Tanya, V. (1993): Comparison of enzyme labeled immunosorbant assay and particle concentration fluorescence immuno-assay with standard serological methods and bacteriological culture for detection of Brucella species infected herd with brucellosis.

Salem, A. A.; El-Gibaly, S. M.; Hassan, M. S. and Hosien, H. I. (1987): Sensitivity of some diagnostic procedures for brucellosis in cattle. Assuit Vet. Med. J., 18: 36.

Schurig, G. G.; Roop, I; Bagchi, T.; Boyle, S.; Buhrman, D. and Sriranganathan, N. (1991): Biological properties of RB 51. Vet. Microb., 28: 171.

Stevens, M. G.; Olsen S. G.; Pugh, G. W. and Breen, D. (1995): Comparison of immune response and resistance to brucellosis in mice vaccinated with Brucella abortus S19 or RB 51. Infec. Immun., 63 (1): 264.

Wilson, W. W. (1972): Eradication of brucellosis. WHO weekly Epidemiol. Rec., 47 (23): 221-228. 